Retrospective Study

\title{
e Combination of Pulsed Radiofrequency with Continuous Radiofrequency Thermocoagulation at Low Temperature Improves Efficacy and Safety in V2/V3 Primary Trigeminal Neuralgia
}

Yuanyuan Ding, MD, PhD ${ }^{1}$, Hongxi Li, MM${ }^{1}$, Tao Hong, MM1, Yongqiang Zhu, MM¹, Peng Yao, MD, PhD'1, and Guangyu Zhou, MD, PhD²

From: ' ${ }^{2}$ epartment of Pain Management, Shengjing Hospital of China Medical University, Shenyang, China; ${ }^{2}$ Department of Nephrology, Shengjing Hospital of China Medical University, Shenyang,

China

Address Correspondence: Guangyu Zhou, MD, PhD

Department of Nephrology Shengjing Hospital of China Medical University

Shenyang 110004, China E-mail: zhougycmu@163.com

Disclaimer: There was no external funding in the preparation of this manuscript. Conflict of interest: Each author certifies that he or she, or a member of his or her immediate

family, has no commercial association (i.e., consultancies, stock ownership, equity interest, patent/licensing arrangements, etc.) that might pose a conflict of interest in connection with the submitted manuscript.

Manuscript received: 02-07-2018 Revised manuscript received: 03-26-2018

Accepted for publication: $04-03-2018$

Free full manuscript: www.painphysicianjournal.com
Background: Primary trigeminal neuralgia (TN) is a common clinical refractory neuralgia. Severe pain is experienced during episodes, severely impacting the patient's quality of life. Long-term suffering from the disease can lead to anxiety, depression, and even suicide. The pathological processes involved in TN are complex, the mechanisms of pathogenesis are unknown, and effective treatment is lacking.

Objective: This study aimed to assess the efficacy and safety of computed tomography (CT)guided pulsed radiofrequency (PRF) combined with low-temperature continuous radiofrequency (CRF) thermocoagulation in V2N3 primary trigeminal neuralgia.

Study Design: This research used a retrospective comparative study design.

Setting: The research took place at Shengjing Hospital of China Medical University.

Methods: A total of 80 hospitalized patients with TN were selected between January 2014 and December 2015 and randomly assigned to 2 groups differentiated by therapeutic method: CRF (CRF group, $n=40$ ) and PRF + CRF (PCRF group, $n=40$ ). Radiofrequency therapy was performed under the guidance of CT. Follow-up measures assessed preoperative conditions, pain remission, complications and side effects, recovery time, and recurrence rate over the 2 years following the surgery.

Results: The Visual Analog Scale (VAS) scores decreased in both groups after surgery. After one month, the decrease in the VAS score in the PCRF group was more apparent, and this difference was maintained for 2 years. The total efficiency rates in the CRF and PCRF groups were $85 \%$ and $97.5 \%$, respectively, at 6 months, 1 year, and 2 years post-surgery. The differences in total efficiency rate of pain between the 2 groups at 6 months, 1 year, and 2 years were statistically significant. Recovery times in the PCRF group were shorter than those in the CRF group. Specifically, recovery times for facial numbness in the CRF and PCRF groups were $3.12 \pm 1.21$ months and $2.23 \pm 1.02$ months, respectively. Recovery times for masticatory muscle weakness were $4.33 \pm 1.54$ months and $3.42 \pm 0.98$ months, respectively.

Limitations: This study is limited by being a retrospective study, and by having a relatively small sample size from a single center.

Conclusions: CT-guided PRF combined with low-temperature CRF thermocoagulation for treating V2N3 primary TN effectively relieves pain, increases late-stage pain remission rate, reduces complications, and reduces the rate of recurrence.

Key words: Complication, continuous radiofrequency thermocoagulation, pulsed radiofrequency, recurrence rate, trigeminal neuralgia, Visual Analog Scale

Pain Physician 2018: 21:E545-E553 
P rimary trigeminal neuralgia (TN) is a common clinical refractory neuralgia. It manifests as unilateral single or multiple distributions, brief recurrent episodes, lightning-like or acupuncture-like pain, existence of "trigger points," and periodic and intermittent attacks. Severe pain experienced during these episodes can have a severe impact on a patient's quality of life. Long-term suffering from the disease can lead to anxiety, depression, and even suicide $(1,2)$. Epidemiological studies have shown that the prevalence of primary TN is about $12.6-28.9$ cases per 10 million and increases with age (3). The pathological processes involved in TN are complex, the mechanisms of pathogenesis are unknown, and effective treatment is lacking.

The treatment of primary TN is divided mainly into drug therapy and surgical treatment, with drug therapy being the preferred approach. Surgical treatment should be considered when drug therapy is ineffective or drug-induced side effects are intolerable; surgical treatments include neurosurgical craniotomy, microvascular decompression, minimally invasive radiofrequency surgery, drug damage (alcohol injection or glycerol rhizotomy), and balloon compression (4-6). Radiofrequency therapy is characterized by small trauma, strong controllability, high safety, accuracy, and repeatability. It is considered a minimally invasive intervention for treating primary TN and has been widely applied (7). The temperature range for continuous radiofrequency (CRF) is $75-95^{\circ} \mathrm{C}$, and it has a satisfactory pain remission rate. At a higher temperature, however, the occurrence of neural injury side effects (e.g., numbness) is higher. The pulsed radiofrequency (PRF) generates current at a temperature not exceeding $42^{\circ} \mathrm{C}$. Therefore, it produces only a permanent regulatory effect on the nerve with almost no nerve damage. PRF does, however, have shortcomings such as a high recurrence rate and slow clinical effects. Due to its special anatomical location at V1, both efficiency and safety should be taken into account in selecting treatment parameters. A previous study explored and reported the radiofrequency treatment for V1 TN (8). Therefore, the CT-guided PRF combined with CRF thermocoagulation at low temperature was selected for this study as the treatment for V2/V3 primary TN, and its clinical effects were observed; secondary and V1 TN were excluded from this study.

Currently, many reports are available about the treatment of TN with radiofrequency $(7,8,10)$. However, the patterns and parameters of radiofrequency vary across studies. There is no consistent standard for treat- ing TN. This study aimed to explore effective treatment methods for V2/V3 primary TN with regard to efficiency, duration of efficient maintenance, complications, and recovery time, with the goal of guiding clinical practice.

\section{Methods}

\section{Patients}

From January 2014 to December 2015, 80 hospitalized patients with TN were selected from the Department of Pain Treatment within the medical universityaffiliated hospital (Fig. 1). The study was approved by the ethics committee of the medical university-affiliated hospital, and all patients were preoperatively informed about the risks and complications. Patients enrolled in the study met the diagnostic criteria for primary TN in the third edition of the International Classification of Headache Disorders (9). In addition, patients had to meet the following inclusion criteria: (1) age > 30 years; (2) lesions of single V2 or V3 branch distribution, or combined V2 and V3 branch distribution; (3) moderateto-severe pain as indicated by an average pain intensity score 24 hours before admission of $>5$ points on the Visual Analog Scale (VAS); (4) natural course having lasted more than 3 months; and (5) history of standard drug treatment in the earlier stage, during which pain was not alleviated by oral medications such as carbamazepine, or side effects were intolerable. The exclusion criteria were as follows: (1) secondary TN, as determined by routine head and trigeminal nerve magnetic resonance imaging examination before surgery; (2) TN with $\mathrm{V} 1$ branch lesion, due to the risk and complications associated with the V1 branch; (3) local infection in the puncture area; (4) mental illness, mental retardation, or unconsciousness; (5) serious liver, kidney, heart, or lung diseases; and (6) coagulation dysfunction before surgery and local anesthetic drug allergy. Patients were screened according to inclusion and exclusion criteria and randomly assigned to 2 groups: CRF (CRF group, $n$ $=40)$ and PRF + CRF (PCRF group, $\mathrm{n}=40$ ).

\section{Surgical Procedure}

Patients in the CRF group ( $n=40$ ) underwent CRF at $68^{\circ} \mathrm{C}$ for 180 seconds. Patients in the PCRF group underwent PRF at $42^{\circ} \mathrm{C}$ for 600 seconds, followed by $\mathrm{CRF}$ at $68^{\circ} \mathrm{C}$ for 180 seconds. Venous access was established preoperatively, and ceftriaxone sodium (Shanghai Roche Pharmaceuticals Co. Ltd., China) was administered intravenously 30 minutes before surgery to prevent infection. 


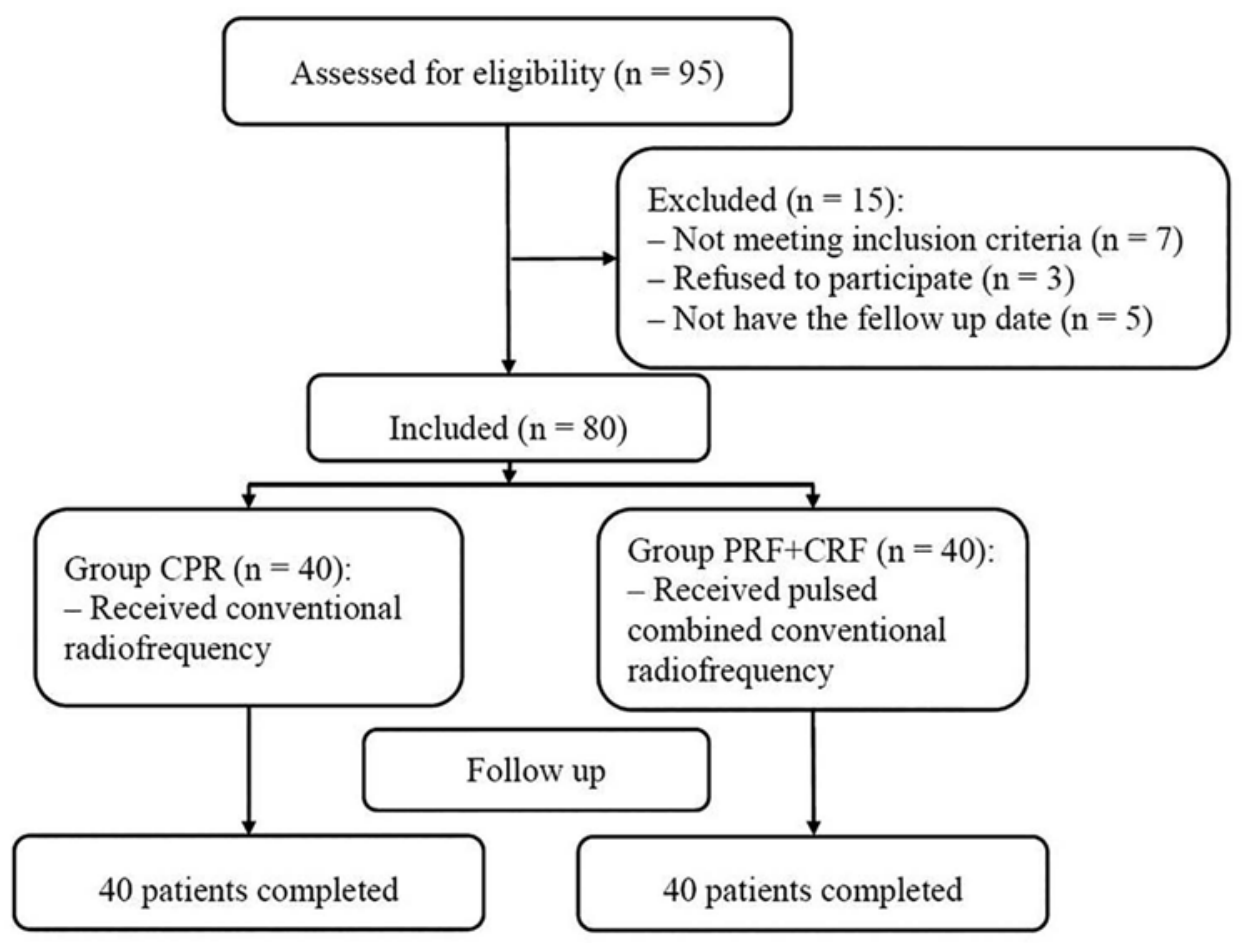

Fig. 1. Study flowchart. All 80 patients were included in the treatment.

CRF, continuous radiofrequency; PCRF, pulsed combined continuous radiofrequency

Patients were placed in a supine position. Under the guidance of computed tomography (CT), the electrode plate of the radiofrequency equipment was attached to the ipsilateral shoulder. Patients' vital signs were intraoperatively monitored. The pre-ganglion semilunar approach was applied and the position confirmed at 2.5-3 $\mathrm{cm}$ lateral to the corner of the mouth on the affected side. The layer-by-layer infiltration anesthesia was performed with $0.5 \%$ lidocaine. Under the guidance of computed tomography $(\mathrm{CT})$, the radiofrequency needle was used to puncture along the established angle and path to the foramen ovale. The CT scan was performed again for confirmation. The direction of the needle was further adjusted to the semilunar ganglion. The radiofrequency equipment (Baylis Medical, Montreal, Canada) was connected for the following tests: (1) sensation was tested at $50 \mathrm{~Hz}$ and $0.1-0.3 \mathrm{~V}$ to observe whether it could induce abnormal pain feeling consistent with presurgery and (2) movement was tested at 2 $\mathrm{Hz}$ and $0.1 \mathrm{~V}$. The submandibular muscle jumped if V3 was affected. The surgeon then observed whether the radiofrequency needle had reached a predetermined position and whether the area of movement and pain after stimulation covered the preoperative site. The position of the needle tip was adjusted until the area of movement and sensation were completely covered, without affecting the normal area. Local anesthesia with $0.2 \mathrm{~mL}$ of $1.5 \%-2 \%$ lidocaine was performed after the needle reached the desired location. The CRF temperature was gradually increased from $50^{\circ} \mathrm{C}$ to the target temperature $\left(50^{\circ} \mathrm{C}-55^{\circ} \mathrm{C}-60^{\circ} \mathrm{C}-68^{\circ} \mathrm{C}\right)$ over 180 seconds. The CRF group underwent CRF at $68^{\circ} \mathrm{C}$ for 180 seconds; the PCRF group underwent PRF at $42^{\circ} \mathrm{C}$ for 600 seconds followed by CRF at $68^{\circ} \mathrm{C}$ for 180 seconds. The patients' response was observed during the surgery, and the range was determined at all the times. The eyelash reflex was assessed to avoid V1 branch injury. The patients were urged to stay in bed for 24 hours after surgery and observed for 2-3 days.

\section{Observations and Follow-up}

Preoperative data including age, gender, course of disease, location of pain, preoperative Visual Analog Scale (VAS) score, and dose of antiepileptic drugs were 
recorded. Follow-up evaluation was performed on the first day and at the end of the first week, first month, third month, sixth month, first year, and second year after surgery. Patients were followed up by nonsurgical group medical staff using the double-blind method. To measure pain, the VAS was used; scoring ranged from 0 points (no pain) to 10 points (the most unbearable pain). Degree of pain relief was assessed according to the World Health Organization's evaluation criteria for pain relief; efficacy was categorized into 4 grades according to subjective symptoms and clinical signs exhibited by the patients, as assessed at different times. The 4 levels of pain relief efficacy are as follows: (a) complete remission (CR), indicating complete resolution of pain; (b) partial remission (PR), indicating significant resolution of pain (50-75\%); (c) mild remission (MR), indicating partial resolution of pain $(<50 \%)$; and (d) no response (NR), indicating no resolution of pain. The significant efficiency rate $(\%)$ is equivalent to $[(C R+P R) / n] \times 100 \%$. The total efficiency rate $(\%)$ is equivalent to $[(C R+P R+$ $\mathrm{MR}) / \mathrm{n}] \times 100 \%$.

In addition, incidence of complications and side effects were measured; these included short-term local bleeding, nausea and vomiting, headache, long-term facial numbness, decreased corneal reflex, and masticatory muscle weakness. Finally, recovery time from long-term side effects as well as recurrence rate was measured.

\section{Statistical Analysis}

Statistical analysis was performed using SPSS Version 19.0 (IBM Corporation, Armonk, NY). The normality of distribution was evaluated using the KolmogorovSmirnov test. Variables with a normal distribution were compared using a one-way analysis of variance, and values were presented as means \pm standard deviations (SD). For variables with an abnormal distribution, the Kruskal-Wallis test was used for comparison, and values were presented as medians (interquartile range). Categorical variables were presented as frequencies and analyzed using the chi-square or Fisher exact test, as appropriate. Two-sided $P$ values $<0.05$ were considered to be statistically significant.

\section{Results}

\section{Needle Position on CT Scan and 3-Dimensional Reconstruction}

All patients underwent surgery successfully. The needle tip could be seen located in the foramen ovale on the CT scan plane, and the needle's path in the foramen ovale was verified by 3-dimensional reconstruction (Fig. 2).

\section{Patient Characteristics}

Basic preoperative conditions were compared between the 2 groups. No significant differences in gen-

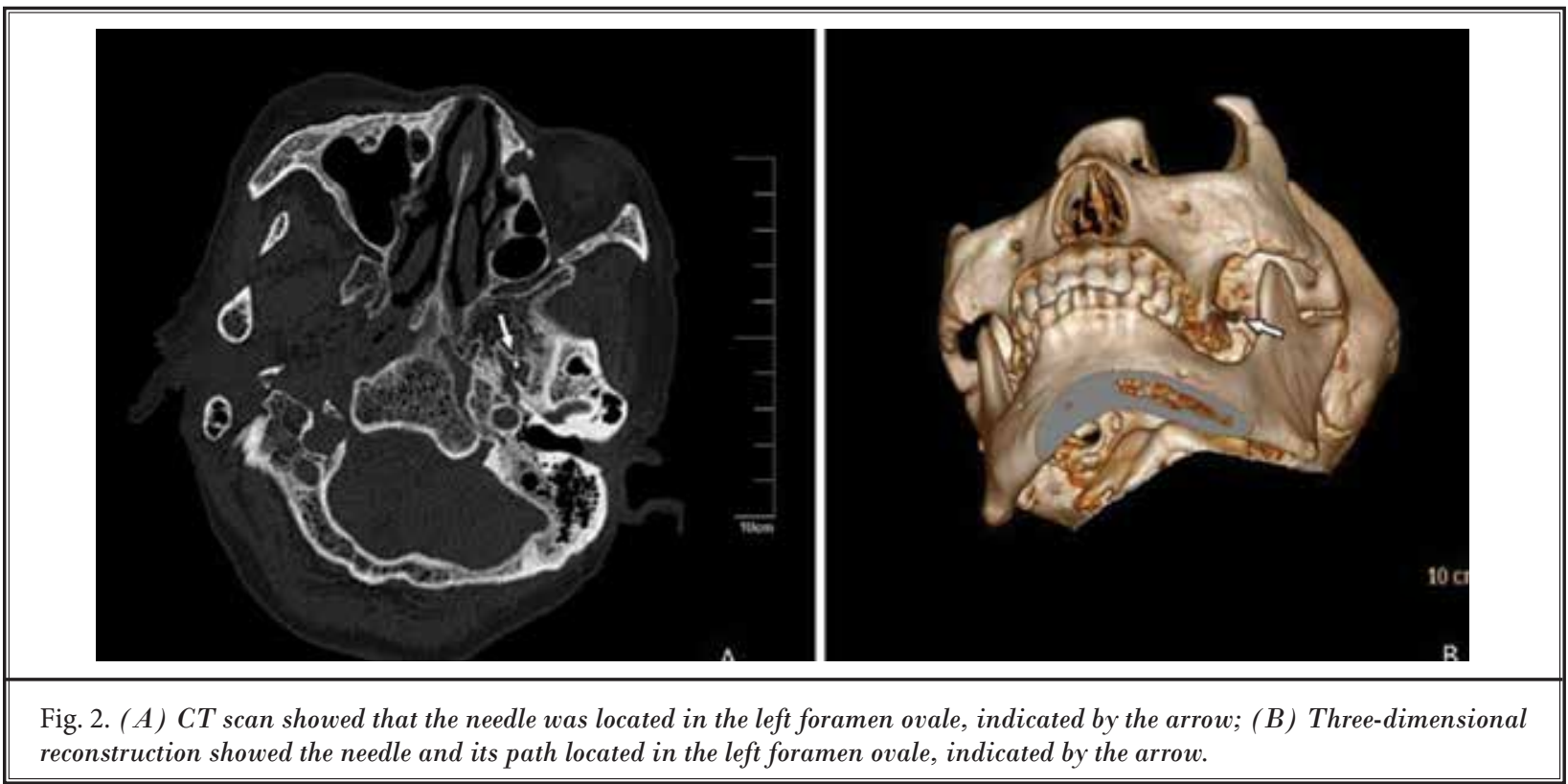


PRF with RF Thermocoagulation Improves the Efficacy and Safety in Trieminal Neuralgia

Table 1. Preperative patient characteristics in the 2 groups.

\begin{tabular}{|c|c|c|}
\hline \multirow{2}{*}{ Parameters } & \multicolumn{2}{|c|}{ Group } \\
\hline & CRF & PCRF \\
\hline Patients (n) & 40 & 40 \\
\hline Gender (Women/Men, \%) & $25(62.5) / 15(37.5)$ & $26(65.0) / 14(35.0)$ \\
\hline Age (Yrs, Range) & $56.42 \pm 9.31(33-73)$ & $55.83 \pm 10.64(34-76)$ \\
\hline Presurgery Pain Duration (M, Range) & $10.5 \pm 6.42(6-23)$ & $10.7 \pm 6.26(5-25)$ \\
\hline \multicolumn{3}{|l|}{ Pain Side (n, \%) } \\
\hline Right & $22(55.0)$ & $21(52.5)$ \\
\hline Left & $16(40.0)$ & $17(42.5)$ \\
\hline Both & $2(5.0)$ & $2(5.0)$ \\
\hline \multicolumn{3}{|l|}{ Branches Affected (n, \%) } \\
\hline V2 & $12(30.0)$ & $11(27.5)$ \\
\hline V3 & $13(32.5)$ & $14(35.0)$ \\
\hline $\mathrm{V} 2 \mathrm{~V} 3$ & $15(37.5)$ & $15(37.5)$ \\
\hline Presurgery VAS & $7.43 \pm 1.72$ & $7.60 \pm 1.82$ \\
\hline \multicolumn{3}{|l|}{ Presurgery Drug Dosage } \\
\hline Carbamazepine (mg/day, n) & $554.43 \pm 82.31(22)$ & $545.23 \pm 79.86(24)$ \\
\hline Gabapentin (g/day, n) & $2.01 \pm 0.33(9)$ & $2.23 \pm 0.41(8)$ \\
\hline Pregabalin (mg/day, $n$ ) & $421.23 \pm 72.47(9)$ & $426.21 \pm 76.41(8)$ \\
\hline
\end{tabular}

CRF, continuous radiofrequency; PCRF, pulsed combined continuous radiofrequency; VAS, Visual Analog Scale. Data are presented as numbers (\%) of patients or mean $\pm \mathrm{SD}$.

der, age, duration of preoperative pain, pain location, affected nerves, preoperative VAS score, or dose of antiepileptic drugs (e.g., carbamazepine) were found between the groups $(P>0.05)$ (Table 1$)$.

\section{Pain Score}

The VAS scores were significantly lower in both groups compared to pre-surgery scores $(P<0.05)$. At one month, the VAS score in the PCRF group was significantly lower than that of the CRF group. By 6 months, the VAS score had increased in the CRF group, while the duration of pain relief was longer in the PCRF group. The VAS score in the PCRF group was significantly lower than that of the CRF group in the later stages of follow-up and remained significantly lower at each time point from 1 month to 2 years $(P<0.05)$ (Fig. 3).

\section{Degree of Pain Relief}

Pain relief was observed immediately in both groups, one day after surgery, with significant pain relief after one week. The pain relief was effective for patients in both groups at discharge. The significant efficiency rate in the PCRF group was higher than that in the CRF group, but this difference was not statisti- cally significant $(P>0.05)$. The total efficiency rates in the CRF group and PCRF group were $85 \%$ and $97.5 \%$, respectively, after 6 months, 1 year, and 2 years; these differences were statistically significant $(P<0.05)$ (Table 2).

\section{Complications and Side Effects}

The surgeries were completed within 30 minutes in patients of both groups during hospitalization. Local bleeding, nausea, vomiting, and headache, which occurred in both groups after surgery, were quickly recovered after local cold compress, symptomatic treatment, and placement of patients in an absolute supine position. No serious adverse reactions were observed. The main side effects were facial numbness, weakness of masticatory muscles, and weakened corneal reflex. Different degrees of numbness after surgery occurred in all patients and were gradually recovered or reduced within one year. No permanent facial paralysis was observed after surgery. The incidence of weakened corneal reflex was quite low. One case of weakened corneal reflex in each group was recovered to normal within one month. No other more serious or permanent complications and side effects were observed. No significant difference in the incidence of facial numbness, 
weakness of masticatory muscles, or weakened corneal reflex was observed between the 2 groups $(P>0.05)$ (Table 3 ).

\section{Recovery Time for Long-Term Side Effects}

The recovery times for facial numbness in the CRF group and PCRF group were $3.12 \pm 1.21$ and $2.23 \pm 1.02$ (months), respectively. The recovery times for masticatory muscle weakness in the 2 groups were $4.33 \pm 1.54$ and

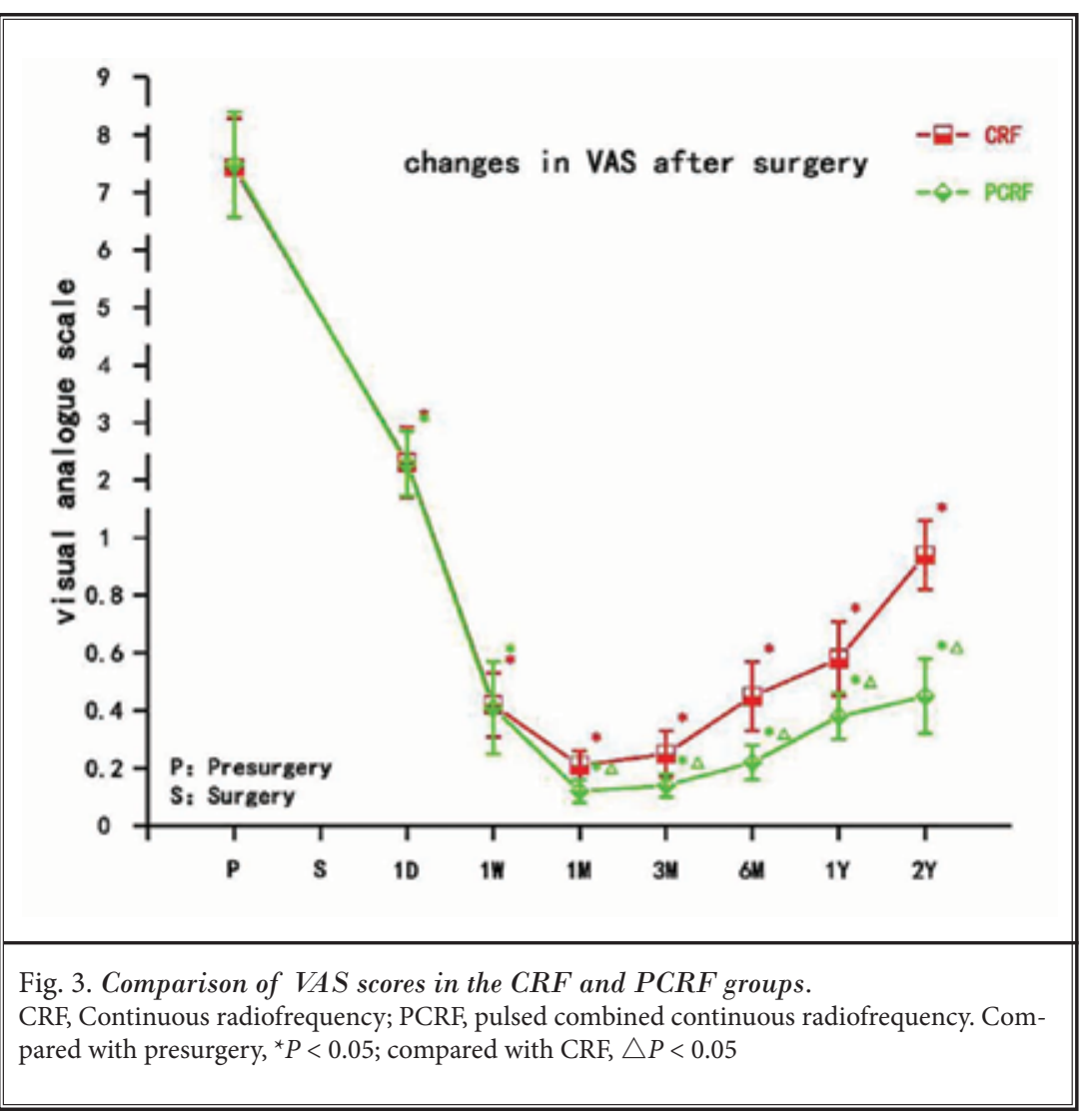

$3.42 \pm 0.98$ (months), respectively. The recovery time for complications in the PCRF group was shorter than that in the CRF group, and the difference was statistically significant $(P<0.05)$ (Table 4).

\section{Recurrence Rate}

The postoperative recurrence rates in the CRF group and PCRF group were $20.0 \%(8 / 40)$ and $5.0 \%$ (2/40), respectively, within 2 years after surgery. The recurrence rate in the PCRF group was lower than that in the CRF group, and the difference was statistically significant $(P<0.05)$.

\section{Discussion}

The pathology and pathogenesis of primary TN are unknown. Moreover, clinically effective treatment for TN is lacking. Therefore, a treatment method with less trauma and fewer side effects is urgently needed. PRF and CRF thermocoagulation have been widely recognized for their success rate, efficacy, safety, and patient satisfaction $(10,11)$, and have gradually become one of the mainstream approaches to treating TN.

At present, radiofrequency thermocoagulation is the most effective minimally invasive technique

Table 2. Comparison of degree of pain relief in the 2 groups (\%).

\begin{tabular}{|c|c|c|c|c|c|c|c|c|c|c|c|c|}
\hline \multirow{2}{*}{$\begin{array}{l}\text { Time After } \\
\text { Surgery }\end{array}$} & \multicolumn{4}{|c|}{ CRF } & \multicolumn{4}{|c|}{ PCRF } & \multicolumn{2}{|c|}{$\begin{array}{c}\text { Significant Efficiency } \\
\text { Rate (\%) }\end{array}$} & \multicolumn{2}{|c|}{$\begin{array}{c}\text { Total Efficiency Rate } \\
(\%)\end{array}$} \\
\hline & CR & PR & MR & NR & CR & PR & MR & NR & CRF & PCRF & CRF & PCRF \\
\hline 1 Day & 20 & 13 & 5 & 2 & 19 & 14 & 6 & 1 & 82.5 & 82.5 & 95.0 & 97.5 \\
\hline $1 \mathrm{Wk}$ & 30 & 9 & 1 & 0 & 29 & 10 & 1 & 0 & 97.5 & 97.5 & 100 & 100 \\
\hline $1 \mathrm{Mo}$ & 28 & 9 & 3 & 0 & 30 & 10 & 0 & 0 & 92.5 & 100.0 & 100 & 100 \\
\hline $3 \mathrm{Mos}$ & 25 & 12 & 1 & 2 & 32 & 8 & 0 & 0 & 92.5 & 100.0 & 95.0 & 100 \\
\hline $6 \mathrm{Mos}$ & 19 & 14 & 1 & 6 & 26 & 11 & 2 & 1 & 82.5 & 92.5 & 85.0 & $97.5^{*}$ \\
\hline $1 \mathrm{Yr}$ & 18 & 15 & 1 & 6 & 25 & 13 & 1 & 1 & 82.5 & 95.0 & 85.0 & $97.5^{\star}$ \\
\hline 2 Yrs & 18 & 15 & 1 & 6 & 25 & 12 & 2 & 1 & 82.5 & 92.5 & 85.0 & $97.5^{*}$ \\
\hline
\end{tabular}

CRF, continuous radiofrequency; PCRF, pulsed combined with continuous radiofrequency; CR, complete remission; PR, partial remission; MR, mild remission; NR, no response. Compared with $\mathrm{CRF},{ }^{*} P<0.05$. 
for treating TN. It involves high-temperature effects of high-frequency current on the semilunar ganglia. The protein of small nerve fibers (A $\delta$ - and C-type fibers) for pain transmission is coagulated and denatured (12). The action potential is hindered, and the purpose of analgesia is achieved (13). Therefore, the temperature is vital in achieving efficacy and lowering recurrence rate after thermal coagulation. Tang et al (14) compared the effects of low $\left(<75^{\circ} \mathrm{C}\right)$ and high temperatures $(>$ $80^{\circ} \mathrm{C}$ ) in treating $\mathrm{TN}$ and found no significant difference in the long-term painless rate between the 2 groups. However, side effects such as numbness were severe and lasted for a long time in the high-temperature group. Yao et al (15) compared effects in the low-temperature group $\left(62,65\right.$, and $\left.68^{\circ} \mathrm{C}\right)$, but the recurrence rate was significantly increased with $62^{\circ} \mathrm{C}$ and $65^{\circ} \mathrm{C}$. A previous study found that the $68^{\circ} \mathrm{C}$ radiofrequency coagulation had fewer complications and achieved a higher level of satisfaction compared with $75^{\circ} \mathrm{C}(16)$. In that study, PRF was intermittent (pulse frequency was $2 \mathrm{~Hz}$ ) with 300-500 kHz current, which was released in 20-ms-short intermittent pulses, and then in 480-ms-long intermittent silent phases; this method was able to make the heat spread, and the effect of nerve damage was quite low (17). In a prospective, randomized, double-blind study, Erdine et al (18) used semilunar ganglion PRF $\left(42^{\circ} \mathrm{C}, 2 \mathrm{~Hz}, 120 \mathrm{~s}\right)$ to treat TN. The short-term remission rate was only $10 \%$. All of the patients relapsed after 3 months. The treatment effect was relatively poor, and the recurrence rate significantly increased. Finally, continuous radiofrequency thermocoagulation treatment was performed in all patients.

It is generally believed that the effect of pure PRF treatment in TN needs discussion, which is why the present study included no separate PRF group. It was necessary to find a therapeutic method that would not only destroy the fibers carrying pain and warm sensations, but that would not affect the function of the tactile fibers, while reducing complications. Luo et al $(19,20)$ found that increasing the voltage of pulsed radiofrequency could effectively increase the remission rate of PRF in treating TN. However, the recurrence rate was still high. Our study further supports the conclusion that PRF treats the TN through its electric field effects rather than through temperature effects. PRF combined with low-temperature continuous radiofrequency thermocoagulation was used in this study to combine the advantages of the 2 treatment methods. It was observed that the pain was significantly relieved
Table 3. Complications and side effects in the 2 groups (\%).

\begin{tabular}{|l|c|c|}
\hline \multirow{2}{*}{ Complications and Side Effects } & \multicolumn{2}{|c|}{ Group } \\
\cline { 2 - 3 } & CRF & PCRF \\
\hline Facial hematoma, n (\%) & $6(15.0)$ & $7(17.5)$ \\
\hline Nausea and vomiting, n (\%) & $1(2.5)$ & $0(0.0)$ \\
\hline $\begin{array}{l}\text { Intracranial hypotension headache, } \mathrm{n} \\
(\%)\end{array}$ & $2(5.0)$ & $1(2.5)$ \\
\hline Facial numbness, n (\%) & $40(100.0)$ & $40(100.0)$ \\
\hline Masticatory muscle weakness, n (\%) & $9(22.5)$ & $10(25.0)$ \\
\hline Decreased corneal reflex, n (\%) & $1(2.5)$ & $1(2.5)$ \\
\hline
\end{tabular}

CRF, continuous radiofrequency; PCRF, pulsed combined continuous radiofrequency

Table 4. Recovery time for side effects in the 2 groups (mos).

\begin{tabular}{||l|c|c|}
\hline \multirow{2}{*}{\multicolumn{1}{|c|}{ Side Effects }} & \multicolumn{2}{c|}{ Group } \\
\cline { 2 - 3 } & CRF & PCRF \\
\hline Facial numbness & $3.12 \pm 1.21$ & $2.23 \pm 1.02^{\star}$ \\
\hline Masticatory muscle weakness & $4.33 \pm 1.54$ & $3.42 \pm 0.98^{*}$ \\
\hline
\end{tabular}

CRF, continuous radiofrequency; PCRF, pulsed combined continuous radiofrequency. Compared with $\mathrm{CRF},{ }^{\star} P<0.05$

one week after surgery in the 2 groups and then gradually reduced. It was considered to be related to the local lesions caused by early surgery and local edema damage. When the edema disappeared, the degree of pain gradually stabilized. The pain relief in the PCRF group was maintained for a long time. This difference lasted from 1 month to 2 years. During the follow-up, a statistically significant difference in the total efficiency rate was found between the 2 groups 6 months, 1 year, and 2 years after surgery, indicating that PCRF had superposition analgesic effects on $\mathrm{TN}$, but that the onset of the effect was slow and maintained for a long time.

In addition to the treatment effect, complications are also important in evaluating the effectiveness of a treatment method. First of all, the method should reduce the side effects of surgery and repeated puncture, thereby reducing complications. Therefore, in this study, the location of the foramen ovale was judged under the guidance of a CT scan. The optimal needle route was selected, and the depth and angle of the needle were measured to achieve accurate puncture and location. Meanwhile, the depth of the needle in the foramen ovale was measured to effectively reduce the puncture damage. Another key factor that influences the occurrence of complications is the temperature. CRF is a high-frequency current generated by the radiofrequency instrument to induce ion oscillation 
within the tissue. The tissue is then heated, the local temperature is increased, and the nerves are damaged for therapeutic purposes. The high temperature can cause cell apoptosis and necrosis. The eschar produced at $80^{\circ} \mathrm{C}$ can cause significant damage to neurons and nerve fibers $(21,22)$. The PRF current is intermittently generated for dissipation of heat. In a study by Podhajsky et al, histological examination showed that $42^{\circ} \mathrm{C}$ PRF on dorsal root ganglions and sciatic nerves in rats resulted in transient neuroendothelial edema and collagenous deposits with no structural changes (23). Erdine et al found axon ultrastructural damage, abnormal membrane and mitochondria, and collapse of microtubules and microfilaments as observed under the electron microscope (24). In a study by Tun et al, the myelin structure in the myelinated axon was destroyed (25). However, all of these changes were reversible. Further, $42^{\circ} \mathrm{C}$ was considered as the temperature boundary to observe whether the tissue damage was reversible. In other words, the analgesic effect of PRF was not achieved by damaging the nerve, but possibly through neuromodulation $(26,27)$. Studies have shown that the effects of PRF may be at the microscopic or even subcellular levels (28). Higuchi et al (29) and Van Zundert et al (30) found that PRF could induce c-fos gene (immediate early gene) upregulation in the neurons of laminas I, II, and IV of the spinal dorsal horn. Hamann et al (31) found that PRF significantly increased the expression of activating transcription factor 3 in the rat dorsal root ganglion. Cahana et al (32) found, through in vivo experiments, that PRF could regulate the synaptic plasticity of nerve cells. At the cytokine levels, PRF could upregulate the expression of glia cell line-derived neurotrophic factor (33), decrease the presynaptic release of glutamate and citrulline (34), and induce spinal descending inhibitory pathways via 5-hydroxytryptamine 3 and $\alpha 2$ receptors (35). However, Choi et al (36) found that the expression of inflammatory proteins in the PRF and CRF groups was upregulated. The upregulated expression of inflammatory cytokines in the PRF group returned to normal after one month. However, the expression in the CRF group continuously and significantly increased. The PRF group showed only mild axonal injury and some mitochondrial swelling, but the CRF group showed irreversible changes in the ultrastructure of sciatic nerve fibers. It was therefore believed that PRF-induced pain relief might be due to the temporary blockage of neural signals by reversible neurons through the nerve conduction pathway, whereas CRF-induced pain relief might be achieved by the permanent blockage of neural signals through other neural pathways. The present study found that PCRF treatment can promote recovery from side effects in the later stage and effectively reduce the recurrence rate, which might be related to the slow regulation effect of neuromodulation signals. Our findings are consistent with previous reports that the combination of PRF and CRF helped in eliminating postoperative complications and side effects (37).

\section{Conclusions}

In summary, CT-guided PRF combined with lowtemperature CRF thermocoagulation for treating V2/ V3 primary TN can effectively relieve pain, increase the pain remission rate in the late stage, reduce complications, and reduce the recurrence rate. Hence, it may be a choice for treating TN.

\section{References}

1. Devor M, Wood I, Sharav Y, Zakrzewska JM. Trigeminal neuralgia during sleep. Pain Pract 2008; 8:263-268.

2. Puskar KR, Droppa M. Trigeminal neuralgia: Pain, pricks, and anxiety. J Gerontol Nurs 2015; 41:8-12.

3. Van Hecke O, Austin SK, Khan RA, Smith $\mathrm{BH}$, Torrance N. Neuropathic pain in the general population: A systematic review of epidemiological studies. Pain 2014, 155:654-662.
4. Yadav YR, Nishtha Y, Sonjjay P, Vijay P, Shailendra R, Yatin K. Trigeminal Neuralgia. Asian J Neurosurg 2017; 12:585-597.

5. Cheng JS, Lim DA, Chang EF, Barbaro NM. A review of percutaneous treatments for trigeminal neuralgia. Neurosurgery 2014; 10:25-33.

6. Han KR, Kim C. Brief report: The longterm outcome of mandibular nerve block with alcohol for the treatment of trigeminal neuralgia. Anesth Analg 2010; 111:550-553.
7. Guo J, Dong X, Zhao X. Treatment of trigeminal neuralgia by radiofrequency of the Gasserian ganglion. Rev Neurosci 2016; 27:739-743.

8. Yao P, Hong T, Zhu YQ, Li HX, Wang ZB, Ding YY, Ma JM, Pan SN. Efficacy and safety of continuous radiofrequency thermocoagulation plus pulsed radiofrequency for treatment of $V_{1}$ trigeminal neuralgia: A prospective cohort study. Medicine (Baltimore) 2016; 95:e5247.

9. Headache Classification Committee 
of the International Headache Society (IHS). The international classification of headache disorders, 3 rd edition (beta version). Cephalalgia 2013; 33:629-808.

10. Taha JM, Tew JM Jr, Buncher CR. A prospective 15 -year follow-up of 154 consecutive patients with trigeminal neuralgia treated by percutaneous stereotactic radiofrequency thermal rhizotomy. J Neurosurg 1995; 83:989-993.

11. Zakrzewska JM, Jassim S, Blum JS. A prospective, longitudinal study on patients with trigeminal neuralgia who underwent radiofrequency thermocoagulation of the Gasserian ganglion. Pain 1999; 79:51-58.

12. Mittal B, Thomas DG. Controlled thermocoagulation in trigeminal neuralgia. J Neurol Neurosurg Psychiatry 1986; 49:932-936.

13. Zhou X, Liu Y, Yue Z, Luan D, Zhang $\mathrm{H}$, Han J. Comparison of nerve combing and percutaneous radiofrequency thermocoagulation in the treatment for idiopathic trigeminal neuralgia. Braz J Otorhinolaryngol 2016; 82:574-579.

14. Tang YZ, Jin D, Bian JJ, Li XY, Lai GH, $\mathrm{Ni}$ JX. Long-term outcome of computed tomography-guided percutaneous radiofrequency thermocoagulation for classic trigeminal neuralgia patients older than 70 years. J Craniofac Surg 2014; 25:1292-1295.

15. Yao $P$, Deng $Y Y$, Hong $T$, Wang ZB, $M a$ JM, Zhu YQ, Li HX, Ding YY, Pan SN. Radiofrequency thermocoagulation for $V_{2} / V_{3}$ idiopathic trigeminal neuralgia: Effect of treatment temperatures on long-term clinical outcomes. A cohort study. Medicine (Baltimore) 2016; 95:e4019.

16. Yao $\mathrm{P}$, Hong $\mathrm{T}$, Wang ZB, Ma JM, Zhu $Y Q$, Li HX, Ding YY, Jiang CL, Pan SN. Treatment of bilateral idiopathic trigeminal neuralgia by radiofrequency thermocoagulation at different temperatures. Medicine (Baltimore) 2016; 95:e4274.

17. Huang RY, Liao CC, Tsai SY, Yen CT, Lin $\mathrm{CW}$, Chen TC, Lin WT, Chang $\mathrm{CH}$, Wen YR. Rapid and delayed effects of pulsed radiofrequency on neuropathic pain: Electrophysiological, molecular, and behavioral evidence supporting longterm depression. Pain Physician 2017; 20:E269-E283.
18. Erdine S, Ozyalcin NS, Cimen A, Celik M, Talu GK, Disci R. Comparison of pulsed radiofrequency with conventional radiofrequency in the treatment of idiopathic trigeminal neuralgia. Eur ] Pain 2007; 11:309-313.

19. Luo F, Meng L, Wang T, Yu X, Shen Y, Ji N. Pulsed radiofrequency treatment for idiopathic trigeminal neuralgia: A retrospective analysis of the causes for ineffective pain relief. Eur J Pain 2013; 17:1189-1192.

20. Luo F, Wang T, Shen Y, Meng L, Lu J, Ji $\mathrm{N}$. High voltage pulsed radiofrequency for the treatment of refractory neuralgia of the infraorbital nerve: A prospective double-blinded randomized controlled study. Pain Physician 2017; 20:271-279.

21. Maarrawi J, Kobaiter-Maarrawi S, Ghanem I, Ali Y, Aftimos G, Okais N, Samaha E. Pathological effects and motor response threshold changes following radiofrequency application at various distances from the L-5 nerve root: An experimental study. J Neurosurg Spine 2011; 15:285-291.

22. Vatansever D, Tekin I, Tuglu I, Erbuyun K, Ok G. A comparison of the neuroablative effects of conventional and pulsed radiofrequency techniques. Clin J Pain 2008; 24:717-724.

23. Podhajsky RJ, Sekiguchi Y, Kikuchi S, Myers RR. The histologic effects of pulsed and continuous radiofrequency lesions at 42 degrees $C$ to rat dorsal root ganglion and sciatic nerve. Spine (Phila Pa 1976) 2005; 30:1008-1013.

24. Erdine S, Bilir A, Cosman ER, Cosman ER Jr. Ultrastructural changes in axons following exposure to pulsed radiofrequency fields. Pain Pract 2009; 9:407-417.

25. Tun K, Cemil B, Gurcay AG, Kaptanoglu E, Sargon MF, Tekdemir I, Comert A, Kanpolat Y. Ultrastructural evaluation of pulsed radiofrequency and conventional radiofrequency lesions in rat sciatic nerve. Surg Neurol 2009; 72:496-500.

26. Cahana A, Zundert J, Macrea L, van Kleef $M$, Sluijter M. Pulsed radiofrequency: Current clinical and biological literature available. Pain Med 2006; 7:411-423.

27. Rehman SU, Khan MZ, Hussain R, Jamshed $A$. Pulsed radiofrequency modulation for lingual neuralgia. Br J Oral Maxillofac Surg 2012; 50:e4-e5.
28. Cosman ER Jr, Cosman ER Sr. Electric and thermal field effects in tissue around radiofrequency electrodes. Pain Med 2005; 6:405-424.

29. Higuchi Y, Nashold BS, Sluijter ME, Cosman E, Pearlstein RD. Exposure of the dorsal root ganglion in rats to pulsed radiofrequency currents activates dorsal horn lamina I and II neurons. Neurosurgery 2002; 50:850-856.

30. Van Zundert J, de Louw AJ, Joosten EA, Kessels AG, Honig W, Dederen PJ, Veening JG, Vles JS, van Kleef M. Pulsed and continuous radiofrequency current adjacent to the cervical dorsal root ganglion of the rat induces late cellular activity in the dorsal horn. Anesthesiology 2005; 102:125-131.

31. Hamann W, Abou-Sherif S, Thompson $S$, et al. Pulsed radiofrequency applied to dorsal root ganglia causes a selective increase in $\mathrm{ATF}_{3}$ in small neurons. Eur J Pain 2006; 10:171-176.

32. Cahana A, Vutskits L, Muller D. Acute differential modulation of synaptic transmission and cell survival during exposure to pulsed and continuous radiofrequency energy.] Pain 2003; 4:197-202.

33. Jia Z, Ren H, Li Q, Ji N, Luo F. Pulsed radiofrequency reduced neuropathic pain behavior in rats associated with upregulation of GDNF expression. Pain Physician 2016; 19:49-58.

34. Yang $\mathrm{CH}$, Chen $\mathrm{KH}$, Huang HW, SheenChen SM, Lin CR. Pulsed radiofrequency treatment attenuates increases in spinal excitatory amino acid release in rats with adjuvant-induced mechanical allodynia. Neuroreport 2013; 24:431-436.

35. Hagiwara S, Iwasaka H, Takeshima N, Noguchi T. Mechanisms of analgesic action of pulsed radiofrequency on adjuvant-induced pain in the rat: Roles of descending adrenergic and serotonergic systems. Eur J Pain 2009; 13:249-252.

36. Choi S, Choi HJ, Cheong Y, Chung $\mathrm{SH}$, Park HK, Lim YJ. Inflammatory responses and morphological changes of radiofrequency-induced rat sciatic nerve fibres. Eur J Pain 2014; 18:192-203.

37. Zhao WX, Wang Q, He MW, Yang LQ, Wu BS, Ni JX. Radiofrequency thermocoagulation combined with pulsed radiofrequency helps relieve postoperative complications of trigeminal neuralgia. Genet Mol Res 2015; 14:7616-7623. 
